\title{
La educación y el verdadero valor del comunicador
}

\section{Resumen}

Los comunicadores influyen tanto en los procesos culturales que se desarrollan a través de los medios y lo que es más importante, en la conducta de masas, que hoy en día se han constituido en la parte más decisiva del proceso de comunicación pues tienen la enorme responsabilidad de administrar un derecho que surge del compromiso que adquiere con la sociedad en el ejercicio de dicha responsabilidad: el derecho a la información. Su servicio a la sociedad pasa por la permanente formación personal y profesional y la concienciación de su responsabilidad. $\mathrm{Y}$, en este sentido procede profundizar en potencialidades que, más allá de lo puramente tecnológico se encuadren en la misión que todo comunicador tiene como garante de un derecho fundamental de la ciudadanía.

Palabras clave: Comunicación; Formación; Comunicadores; Responsabilidad; Misión.

\author{
Humberto Martínez-Fresneda \\ Professor da Universidade \\ Francisco de Vitoria. Doutor em \\ Ciências da Informação pela \\ Universidade Complutense de \\ Madrid - Espanha \\ h.fresneda@ufv.es
}

\footnotetext{
Para citar este artigo:

MARTÍNEZ-FRESNEDA, Humberto La educación y el verdadero valor del comunicador. Revista Linhas. Florianópolis, v. 17, n. 33, p. 29-47, jan./abr. 2016.
}

DOI: $10.5965 / 1984723817332016029$

http://dx.doi.org/10.5965/1984723817332016029 


\section{Education and the true $A$ educação e o verdadeiro value of communicator valor do comunicador}

\begin{abstract}
Communicators influence both, on the cultural processes that take place through the media and what is more important, on mass behavior, which today has become the most decisive part of the communication process as communicators have the enormous responsibility of giving a right that arises from the commitment acquired with society in the exercise of this responsibility: the right to information. Their service to society goes through personal and professional standing and awareness of their responsibility. And in this sense should deepen on potentials, beyond the purely technological fit into the mission that every community is to guarantee a basic right of citizenship.
\end{abstract}

Keywords: Communication; Formation; Communicators; Responsibility; Mission.

\begin{abstract}
Resumo
Os comunicadores influem tanto nos processos culturais que se desenvolvem através das mídias, e o que é mais importante, na conduta das massas, que hoje em dia se constituíram na parte mais decisiva do processo de comunicação, pois têm a enorme responsabilidade de administrar um direito que surge do compromisso que adquire com a sociedade no exercício de dita responsabilidade: o direito à informação. Seu serviço à sociedade passa pela permanente formação pessoal e profissional e a tomada de consciência da sua responsabilidade. $E$, neste sentido, cumpre aprofundar em potencialidades que, para além do puramente tecnológico, se enquadrem na missão que todo comunicador tem como garantidor de um direito fundamental de cidadania.
\end{abstract}

Palavras-chave: Comunicação; Formação; Comunicadores; Responsabilidade; Missão. 
El papel de los medios de comunicación como educadores de la sociedad ya no es una hipótesis con la que trabajar a medio plazo. Los medios de comunicación en la sociedad del siglo XXI forman parte intrínseca del desarrollo de las sociedades modernas y suponen una revolución que afecta a todos los terrenos de la vida social, institucional y personal.

Las audiencias (la televisión tiene el 88,5 \% de penetración según la última oleada abril de 2014 a marzo de 2015-, del Estudio General de Medios, la radio, el 60,4 \%, los diarios, el 29,1\% o internet, el 62,4\%) se ponen en contacto con muchos ámbitos de la realidad gracias los medios. Esto supone, como mínimo, un diálogo social que refuerza actitudes personales y sociales. A esta relación continua e inmediata entre medios de comunicación y receptores, algún autor ha denominado dialéctica informativa, de la que hablaremos más adelante.

Los medios de comunicación al trabajar con la actualidad reflejan nuestra cultura contemporánea. Son un referente de primer orden dentro de la sociedad actual. $Y$ un referente que apuesta claramente por la transmisión de valores o contravalores, según se mire, que termina universalizando por consenso implícito la sociedad que los recibe.

Es necesario, por tanto, asumir que los medios de comunicación intervienen directamente en la educación de la sociedad.

En este sentido, resulta relevante preguntarse cuáles son aquellas actitudes dentro de la profesión periodística que favorecen la misión del comunicador. Es decir, qué herramientas debe utilizar un comunicador para desempeñar su función de la manera más rigurosa y completa.

A lo largo de este artículo se va a indagar en el papel del comunicador tomando como referencia la actividad de la comunicación y su relación con la educación y ya más concretamente la actividad de los comunicadores como líderes sociales. Para ello, se hace una profunda revisión teórica que pone en contacto la comunicación con la educación y ambas con el comunicador. 


\section{l compromiso de la comunicación como herramienta educativa}

Es incuestionable que los medios de comunicación tienen en la propia vida su argumento principal. Para la eficaz transmisión y penetración de sus mensajes en la sociedad se sirven de realidades fácilmente reconocibles por la propia sociedad y que constituyen su propia vida. Son hechos que forman parte del día a día de la sociedad. La actualidad es, en ocasiones, la excusa perfecta para que los medios de comunicación introduzcan las preocupaciones de una sociedad demasiado entregada a la hipnosis de una imagen, el sensacionalismo de un gran titular o la atracción de una voz profunda a través de la radio.

Esto desemboca en la transmisión de una serie de valores, ideas y pensamientos que se pueden utilizar para desarrollar/anular la capacidad crítica de quien los recibe.

A partir de aquí, deberíamos reconocer que los medios de comunicación son una herramienta de educación que se ofrece al receptor como una primera aproximación a una realidad en la que va a tener que desenvolverse como ciudadano con plenos derechos y deberes. El problema está en dilucidar si los medios de comunicación ofrecen "su realidad" con todos los condicionamientos políticos, ideológicos, económicos y sociales que tienen o si su responsabilidad, derivada del reconocimiento de la influencia de los medios en la sociedad, les hace ofrecer la verdad, entendida como reflejo de lo cierto, respetando los hechos en cuanto datos reales.

Porque los medios de comunicación son un espejo donde mirar todo el acontecer diario, todo lo que sucede a nuestro alrededor más inmediato, en definitiva todo lo que forma parte de los grandes éxitos y fracasos de la humanidad. Los medios de comunicación permiten a la sociedad acercarse a los principales problemas y provocan que no se sea impasible ante ellos, forzando a una toma de posición y decisión personal.

Por eso la sociedad debe estar preparada para saber discernir y tomar posturas creativas y autónomas ante la realidad que vivimos y la que le presentan los medios de comunicación.

El Grupo Comunicar, pionero en el estudio de la relación entre medios de comunicación y sociedad advirtió ya hace años: 
Gran parte de la percepción de la realidad que hoy cualquier ciudadano y ciudadana de este mundo realiza está tamizada y mediatizada en buena medida por los medios de comunicación. Desde la infancia, consumimos altas dosis de comunicación audiovisual, sin ser conscientes de que los medios además de transmitir y reflejar la realidad, también, en cierto modo, la crean y recrean, construyen la realidad. (Aguaded, 1998, p. 7) ${ }^{1}$

Los medios de comunicación, indudablemente, captan la realidad. El problema es que ofrecen una interpretación de esa realidad, de las tendencias y modas que se suceden y por tanto, terminan siendo los grandes arquitectos de la misma.

Esto, necesariamente debe llevar a indagar en los propios medios de comunicación, en sus intereses, en sus estructuras y establecer una radiografía exacta del medio, que permita calibrar su influencia y poder en la sociedad.

La interpretación, el conocimiento que hay que tener de los medios de comunicación tiene su sentido desde el momento en que estos reflejan todas estas situaciones.

En ese sentido se puede decir que la comunicación se ha convertido en uno de los valores más importantes del siglo XXI. Ya nadie discute que, en la actualidad, los medios de comunicación tienen un papel fundamental en la formación de valores y criterios de la sociedad.

Por lo tanto, si los comunicadores tienen sentido lo es en virtud de la habilitación que la sociedad les hace para estar honestamente informada.

Si la comunicación es fundamental para la convivencia entre las sociedades, el comunicador deber responder de manera honesta a esa intermediación entre sociedad y realidad surgida en el seno de la sociedad.

Ser comunicador, por tanto, es ser conscientes del importante papel de esta profesión que actúa de intermediaria entre la realidad y la sociedad. Pero, además, es un compromiso con la comunicación como proceso esencialmente humano.

\footnotetext{
${ }^{1}$ José Ignacio Aguaded pertenece al grupo Comunicar, colectivo andaluz para la Educación en Medios de Comunicación y cuyo ámbito de actuación es la Comunidad Autónoma Andaluza.
} 
El premio Príncipe de Asturias de Comunicación y Humanidades 2003, el periodista polaco Ryszard Kapuscinsky lo expresa claramente cuando afirma la necesidad de recuperar la "función social del periodismo por encima de las necesidades económicas y las ideologías (...). Para ello, hay tres principios inquebrantables para ejercer la profesión: conciencia de labor social que cumple la información, respeto hacia el otro y formación" 2

Parece, por tanto, inexcusable determinar cuál es el perfil del comunicador perfecto. Tarea que no es fácil pero sí necesaria para dignificar una profesión que surge como una necesidad social y que se proyecta como servicio a la sociedad, pero no a una sociedad anónima sino a una sociedad de personas concretas.

Por eso el comunicador debe ser una persona con inquietud formativa que esté más preocupado por llenarse las mochilas de criterio propio que de pura información. Sirva esta anécdota para ilustrar el tema:

Hace más de 100 años que un joven que no tenía más de 21 años, recién llegado a Madrid, manifestaba su deseo de ingresar en el periodismo. Era, a primera vista, un principiante como tantos otros, dominado por una inmensa vocación literaria, muy superior a la que señalaban sus estudios de medicina. Su padre había sido periodista y, por este camino, trataba de seguir la inclinación de escritor.

El joven escribió una carta a don Guillermo Rancés y Esteban que, entonces era director del periódico “EI Tiempo": ${ }^{3}$

“Muy Sr. mío: Hijo de un corresponsal en tiempo de la guerra carlista del antiguo “Tiempo", médico y aficionado a escribir aunque sean gacetillas, me atrevo a dirigirle a Vd. esta carta y a pedirle un sitio por pequeño que sea en la redacción de su periódico con estas condiciones: $1^{\circ}$ escribir gratis, $2^{\circ}$ tener de Pascuas a Ramos una entrada de teatro, y $3^{\circ}$ poder deslizar de vez en cuando un artículo científico. De V.S.S.Q.B.S.M. ${ }^{4}$

Firmaba la carta en Madrid, en noviembre de 1893, Pío Baroja.

\footnotetext{
${ }^{2}$ Declaraciones al diario La Vanguardia, recogidas por Europa Press y publicado el 23 de octubre de 2003 en la weblog de Ramón Salaverría.

${ }^{3}$ Guillermo Rancés y Esteban, tenía 39 años, era amigo íntimo de Silvela, después de haber formado parte de la redacción de "La Epoca” y haber dirigido “La Monarquía”, fundó “El Tiempo”, órgano silvelista. Rancés fue con Silvela, subsecretario de Instrucción Pública y Bellas Artes, ocupó la vicepresidencia de la Asociación de la Prensa de Madrid y fue diputado a Cortes por Santa Cruz de Tenerife.

${ }^{4}$ De Vuestro Seguro Servidor Que Besa Su Mano.
} 
Desde que Baroja escribió esa carta hasta nuestros días, se ha inventado una profesión que atrae a muchas personas y que está en el punto de mira de otras tantas que no dudarán en juzgar la labor comunicativa de una manera muy rigurosa.

Del poder de la comunicación y de los comunicadores está la cita de Balzac a su amigo Léon Gozlan al que confiesa: “No me gusta el periodismo. Puedo decir incluso que lo aborrezco. Es una fuerza ciega, sorda, perversa, rebelde, sin moralidad, sin tradición, sin objetivos concretos y dignos. Es como el carnicero: mata por la noche para comer al día siguiente de lo que han matado. Pero, en fín, inclinémonos ante él. Es una fuerza: es la fuerza suprema de nuestro siglo. Esta fuerza lo mueve todo, conduce a todos los puntos de la circunferencia; es la única que tiene el poder suficiente para derribar, y, por consiguiente, el poder necesario para reemplazar lo que lanza por los suelos".

Por eso es necesario descubrir, cuáles son esas señales que indican a la persona si es consciente de la responsabilidad que asume al inclinarse por los estudios de comunicación.

Esta responsabilidad se deriva del hecho de que el comunicador alimenta de información a millones de personas $\mathrm{y}$, por tanto es referente de esos millones de personas.

Los comunicadores influyen, pueden influir tanto en los conocimientos y lo que es más importante, en la conducta de masas, que hoy en día no se puede frivolizar acerca de su labor. La única realidad es que el periodista debe servir a la sociedad y no servirse de ella, a través de la verdad. Para ello, lo primero es concienciarse de dicha responsabilidad, y después estar en continua alerta para combatir la manipulación, mediante la cultura, la educación y la constante formación personal y profesional.

Y, todo ello dentro del ámbito de la libertad de expresión y la libertad de información porque no se puede apelar a esta última -reconocida en la Constitución Española, de $1978^{5}$ para expresar lo que se quiera, sin ninguna limitación.

\footnotetext{
5 Artículo 20.1.a: "Se reconocen y protegen los derechos: A expresar y difundir libremente los pensamientos, ideas y opiniones mediante la palabra, el escrito o cualquier otro medio de reproducción". Artículo 20.1.d: "A comunicar o recibir libremente información veraz por cualquier medio de difusión. La ley regulará el derecho a la cláusula de conciencia y al secreto profesional en el ejercicio de estas libertades”.
} 
La libertad de información como libertad pública convive con otras libertades públicas y, por ello, es preciso establecer límites.

La propia Constitución Española de 1978 en su artículo 20, punto 4 reconoce estos límites. ${ }^{6}$ En cualquier caso, la libertad de expresión como libertad fundamental está, a su vez, indisolublemente unida a la responsabilidad, es decir, al cumplimiento honesto de los deberes como profesional de la comunicación, tratando de responder fielmente al compromiso que se tiene con la sociedad en la gestión de ese derecho fundamental.

Esta consideración evitaría el déficit de credibilidad que tiene el comunicador por parte de la sociedad y que viene determinado por:

1. La falta de calidad informativa

2. La falta de confianza social

3. El descenso de credibilidad de la información

4. La falta de independencia

\section{Libertad de expresión y responsabilidad}

Es corriente que al hablar de libertad de expresión en el campo de los medios de comunicación se identifique este término con el concepto de libertad y, a su vez, este, con el concepto de independencia. O lo que es lo mismo. Se identifica libertad de expresión con libre albedrío.

El mundo de la comunicación permite así que queden vulnerados ciertos derechos fundamentales que con la excusa del "bien común" se violan indiscriminadamente para lograr los objetivos empresariales de la comunicación.

\footnotetext{
${ }^{6}$ Artículo 20.4 de la Constitución Española de 1978: "Estas libertades tienen su límite en el respeto de a los derechos reconocidos en este Título, en los preceptos de las leyes que lo desarrollan y, especialmente, en el derecho al honor, a la intimidad, a la propia imagen y a la protección de la juventud y de la infancia".
} 
El primer postulado, por tanto, de la libertad de expresión debería ser expresar, defender, divulgar, en definitiva, buscar la verdad. En caso de duda ninguna información debería publicarse.

En definitiva, la dignidad de la profesión periodística exige respeto a la libertad propia (libertad de expresión) y ajena (respeto a los valores de la vida individual, social y familiar).

La libertad de expresión queda ampara en el propio concepto de libertad responsable, es decir, aquella que salvaguarda la libertad de las personas.

La libertad de información o de expresión del periodista no puede disociarse de sus actos, de sus obras. La libertad de informar, de expresión va unida, por tanto, al obrar humano y este a una cierta conciencia de lo que se hace. Gevaert así lo afirma cuando dice que "un hombre obra humanamente cuando se da cuenta de lo que está haciendo" (GEVAERT, 1995, p. 280).

Por lo tanto, el acto humano de informar dimana de una voluntad libre asociada sobre motivos, en alguna medida, conscientemente queridos.

1. En definitiva, para que este acto de informar sea libre debemos tener claro qué es lo que queremos hacer, lo que elegimos hacer. Pero es importante reconocer, igualmente que esta elección no es un acto exclusivamente voluntario sino que también intervienen motivaciones no conscientes.

Cuando uno elige lo que sea, tiene un motivo que puede depender esencialmente de su voluntad pero también pueden existir motivos no voluntarios como por ejemplo "tener dolor de cabeza", lo que hace que tenga que optar por una decisión, "no trabajar y quedarme en casa", provocada por un acto involuntario en el que la voluntad no ha participado de manera activa.

Como afirma Leonard,7 "somos libres, sí, pero para ciertos fines, a la vista de ciertos móviles, al servicio de ciertos valores, expresiones todas ellas en que se

\footnotetext{
${ }^{7}$ Leónard, André, El fundamento de la moral. Madrid, Biblioteca de Autores Cristianos, 1991, p. 79.
} 
traduce la relatividad y, por lo mismo, la finitud de nuestras decisiones". Valores, que también hacen lícita (o no) una elección.

Después preguntarnos por eso que se quiere hacer. ¿Por qué lo quiero hacer? ¿Por qué lo quiero hacer? Por hábitos - nuestros hábitos que de manera involuntaria pueden empujarnos a la acción desde la rutina - o por un ejercicio de libertad. Para ello,

a. Valorar los pros y los contras. Examinar desde la razón las ventajas y los inconvenientes. ¿En este momento es lo adecuado para cada uno tomar esta decisión?

b. Dejar que hablen en su orden la inteligencia, la voluntad y las pasiones.

En este punto, es muy importante el dominio de las emociones. Muchas veces son las que empujan a la voluntad a una determinada opción u otra. Por eso, no se trata de anularlas, sí de reconducirlas, ordenarlas, serenarlas y ponerlas al servicio de nuestros objetivos. Es una manera de autodeterminarse, capacidad que tiene la voluntad.

Leonard afirma que cuando uno dice: "Yo quiero" significa realmente, yo elijo, yo me esfuerzo y yo consiento". (LEONARD, 1997: 22)

Finalmente, tomar la decisión responsable.

Por lo tanto, la libertad humana está unida a la capacidad de elección. Esta opción responsable revierte de manera positiva en el pleno desarrollo del hombre.

$Y$ esta libertad unida indisolublemente a la responsabilidad significa la necesidad de que el hombre justifique su propio actuar en el auténtico desarrollo de su persona.

En este sentido la libertad es la condición por la que el hombre se realiza como sujeto porque da valor a sus propios actos, los legitima, incluso muchas veces en contra de su propia tendencia natural. No en contra de su voluntad pues ésta es la que, en la responsabilidad, controla esos actos. $Y$ es donde, precisamente el hombre es libre. 
Por tanto, "no designa simplemente una capacidad sino una situación personal de madurez". 8

Si el hombre es capaz de tomar en sus propias manos su obrar en cierta medida se posee a sí mismo pues puede desde la opción personal determinar su propia existencia.

El hombre que renuncia a esa responsabilidad no puede ser libre porque renuncia a decidir sin presiones las opciones de vida que más le pueden ayudar a su desarrollo como persona.

Y esta responsabilidad que se deriva de la capacidad de elección del periodista como hombre, indudablemente tiene mucho que ver con el valor de la renuncia como determinación responsable en favor de una libertad absoluta, una libertad responsable que salvaguarda la libertad de las personas e implica sacrificio, no coacción pues se da el valor adecuado y supeditado a otro mayor que representa el desarrollo del hombre como persona.

Si elijo, renuncio. La verdadera responsabilidad está en renunciar a favor de algo que va en beneficio de una libertad mayor. De este modo, esta renuncia no puede ser considerada como una privación de libertad sino como una opción responsable en beneficio del bien común. Es, por tanto, una renuncia a favor de la responsabilidad.

Pero libre no significa que deba desatenderse de toda ley. De ahí se derivaría que para ser libre es esencial estar en desacuerdo con la razón. Cuando lo cierto es, precisamente, lo contrario: el hombre, por ser libre, ha de vivir de acuerdo con la ley pues es la ley la que mueve y le guía a obrar el bien y evitar el mal.

La libertad responsable es la que se identifica con la capacidad de elegir el qué y el cómo de la información en función del bien común.

Lo contrario es un uso irresponsable de la libertad que iría en contra del desarrollo humano.

\footnotetext{
${ }^{8}$ Lucas Lucas, Ramón, El hombre, espíritu encarnado: compendio de filosofía del hombre. Madrid, Sociedad de Educación Atenas, 1995, p. 179.
} 
Ser libre en el campo de los medios de comunicación, por tanto, no se puede identificar, como comentaba al principio, con la absoluta independencia de la sociedad y el mundo, sino con vivir de acuerdo a los valores morales y éticos que deben regir la vida profesional y personal y que le hacen actuar de manera responsable.

Libertad, responsabilidad y amor son los tres pilares sobre los que se construye la auténtica libertad, lo que nos hace hombres, personas. $Y$ este tipo de periodista hombre es el que está en permanente tensión como buscador de la verdad, de la verdad del hombre y de la verdad de Dios.

\section{Potencialidades del comunicador como educador}

Hablar de periodismo es, por tanto, hablar de responsabilidad, es hablar de normas de comportamiento, es hablar de la ética y deontología del profesional de la comunicación y sólo en este contexto tiene sentido hablar de las fuentes en el periodismo informativo.

Porque ser comunicador significa ser conscientes del importante papel de esta profesión que actúa de intermediaria entre la realidad y la sociedad. Pero, además, es un compromiso con la comunicación como proceso esencialmente humano.

De ahí se deriva la responsabilidad del periodista que procede del hecho de que el comunicador alimenta de información a millones de personas y, por tanto es referente de esos millones de personas.

Quizá el código deontológico más explícito en cuanto a la regulación de la práctica periodística es el aprobado por el Colegio Deontológico de Periodistas de Cataluña, del año 1992. Merece la pena destacar, entre otros, los siguientes criterios, que constituyen una verdadera guía de cómo ejercer el periodismo y del papel que cumplen las fuentes de información:

1. Difundir únicamente informaciones fundamentales, evitando en todo caso

afirmaciones o datos imprecisos y sin base suficiente que puedan lesionar 0 menospreciar la dignidad de las personas y provocar daño o descrédito. 
2. Rectificar con diligencia y con tratamiento adecuado a la circunstancia, las informaciones $-y$ las opiniones que se deriven de ellas- cuya falsedad haya sido demostrada y que, por este motivo, resulten perjudiciales para los derechos o intereses legítimos de las personas y/o organismos afectados, sin eludir, si fuera preciso, la disculpa, con independencia de lo que las leyes dispongan al respecto.

3. Utilizar métodos dignos para obtener información o imágenes.

4. $\quad$ Respetar el "off the record" cuando haya sido invocado.

5. No aceptar nunca retribuciones o gratificaciones de terceros por promover, orientar, influir.

6. No utilizar nunca en beneficio propio informaciones privilegiadas, obtenidas de forma confidencial como periodistas en ejercicio de su función informativa.

7. Respetar el derecho de las personas a su propia intimidad e imagen, especialmente en casos o acontecimientos que generen situaciones de aflicción o dolor.

Dignidad de las personas, respeto, honestidad, verdad, son algo más que términos. Son, entre otros, los conceptos que dan sentido a la profesión periodística, al trabajo periodístico.

En la elaboración de una información es donde se materializa la verdadera función del periodista, el servicio a la sociedad cuyo fundamento está en el servicio a la verdad.

Escribir una noticia, un reportaje o una entrevista no es un mero ejercicio mecánico. El periodista debe poner todos sus sentido al servicio de lo que va a escribir y hacerlo con la mayor diligencia.

La responsabilidad de la que hemos hablado obliga al comunicador a reconocer ciertas potencialidades que todo profesional debe aplicar:

1. Conocer su misión como periodista. 
El periodista debe tener una clara responsabilidad social que le obliga a responder de su actuación ante la propia sociedad. Es una responsabilidad en todos los terrenos: fundamentalmente, ante su conciencia. También ante su empresa, ante la profesión, ante la sociedad, con la técnica, con las características y tipos de público, etc.

Para ser diligente debe tener autonomía cultural, debe ser competente (muchas veces la incompetencia de un periodista proviene de una deficiencia moral y no simplemente de una falta de experiencia o de rigor profesional), debe estar preparado profesionalmente y debe tener grandes conocimientos.

Esto le hace ser un referente cierto. Es la clave de su credibilidad. Como afirma Timothy Garton Ash, historiador inglés, "se trata de una cualidad que quizá pueda definirse, sobre todo como veracidad. Nadie va a ser totalmente exacto. Existe un margen de error inevitable y, por así decir, cierta licencia artística para que una realidad confusa y cacofónica se transforme en prosa legible. Pero el lector debe estar convencido de que un autor determinado suele ser exacto, que tiene la genuina intención de reunir todos los datos significativos y que no va a jugar con ellos para obtener un efecto literario". (GARTON, 2000, p. 18-19)

Esto, de manera práctica, significa que el tipo de información para ejercer esta responsabilidad debe ser aquella que sea veraz, objetiva y universal:

- Veraz

La verdad informativa es la verdad lógica (aquella en la que la verdad es la realidad en cuanto que es conocida).

En este caso, conocida por los destinatarios de la información, a través de los medios de comunicación. La verdad informativa, es una verdad derivada. No se sustenta por sí sola. Adecúa la mente con la realidad. Y esa adecuación la realiza el entendimiento del periodista que la puede hacer llegar al destinatario a través suyo.

\section{- Objetiva}

El periodista debe dar a conocer hechos verdaderos, que se pueden comprobar. Es la imparcialidad del periodista con respecto de la realidad que conoce o intenta 
conocer. En definitiva, es una actitud propia del periodista como persona. Es neutralidad, sinceridad, exactitud con los datos que tenemos que transmitir.

- Universal

El periodista debe informar de todo aquello que sea del interés de la mayoría.

2. Ser consciente de su responsabilidad como persona.

Actuar responsablemente significa ensalzar los valores de la persona, dignificar a la persona a través de la información. Una conciencia bien formada y la coherencia entre lo que se vive en la vida personal y la profesional puede dotar al periodista de una visión enriquecedora cuando se enfrente diariamente al juicio de la realidad.

El comunicador debe tener un personal sentido ético en alza y ser coherente para ser sincero en la convivencia social.

Si esto no es así, la información con la que trabaja no podrá ser nunca ética. Sin ética no hay autonomía y, sin esta, no es posible que el periodista sea libre.

Esto no quita para que el comunicador reconozca, además las normas éticas de su profesión. Si no se convierte en sujeto incapaz de actuar responsablemente: se degrada a sí mismo como persona y como profesional y lo que es peor, a medida que su poder e influencia aumentan, se convierte en causa de la degradación de un tal vez amplio número de inocentes.

Bajo la máxima de expresar, defender y divulgar la verdad, debe tener en cuenta el bien común y formarse para informar.

Sólo con probados y sólidos valores éticos, y sólo si conoce cuál es el sentido trascendente de la vida, puede ser capaz el informador de superar una visión relativista y empequeñecida a la hora de enjuiciar los hechos en su actuación profesional.

Y esto no lo abarca ningún código deontológico y ético de la profesión. Ningún código deontológico abarca todo el comportamiento ético del profesional. Por encima de cualquier código deontológico y ético está la Ley Natural. ${ }^{9}$

\footnotetext{
9 Uno de los puntos más polémicos de la regulación de la profesión periodística es el posible carácter sancionador de un supuesto Consejo Estatal de Información, en caso de incumplimiento del Código
} 
Por tanto, los códigos éticos no solucionan el comportamiento ético de los profesionales.

La buena formación de la conciencia y el conocimiento de la ética profesional no pueden darse por supuestos. No se poseen por el hecho de haber nacido, ni se adquieren sin más con el ejercicio rutinario de la profesión. Es algo que, para poder vivirlo, antes hay que aprenderlo. Si no es así, supondría una irresponsabilidad tal que bastaría por sí sola para la autodescalificación profesional de quien así actuase.

\section{Conclusiones}

Las actitudes que deben predominar en un periodista como educador, podrían resumirse en:

1. Capacidad de análisis para saber discernir el valor informativo de una noticia, es decir el interés de esa noticia para la sociedad. El periodista debe preguntarse siempre por el por qué de las cosas, profundizar en las causas. No sólo contar los hechos sino estar preparado para explicarlos.

2. Espíritu crítico para ayudar a la sociedad a conocer la realidad de las cosas. Para ello, el periodista, debe previamente conocerla.

3. Honestidad, para reflejar con fidelidad el hecho informativo. El periodista no debe traicionar los grandes valores universales sino ponerlos al servicio de la información. Esto le hará creíble.

4. Capacidad de comunicación para ser eficaz en la transmisión de la información.

5. El comunicador, por tanto, debe conocer su misión como periodista. Debe tener clara su responsabilidad social que le obliga a responder de su actuación ante la propia sociedad. Es una responsabilidad en todos los terrenos: 
fundamentalmente, ante su conciencia. También ante su empresa, ante la profesión, ante la sociedad, con la técnica, con las características y tipos de público, etc.

6. Responsabilidad. El periodista responsable, por tanto, no tiene entre sus objetivos engañar a la sociedad con su información sino servir al bien común. Por eso, el periodista debe valorar su profesión no sólo de cara a sí mismo, a la realización de sus capacidades, sino también y muy especialmente de cara a su relación con los demás. Debe valorar las consecuencias y efectos, el sentido que su labor tendrá en la sociedad. Y debe buscar la verdad como algo necesario para el bien de todos, para el bien común.

Un periodista responsable es, en definitiva, un periodista inteligente.

7. El periodista debe ser persona antes que periodista y, en cualquier caso, persona periodista. Esto se traduce en cuatro premisas de las que debe partir todo periodista:

a. Un ser moral

La persona periodista es aquella que ha asumido un orden legal-ético, que asume un mundo de valores de los que se responsabiliza y defiende.

b. Un ser con capacidad de aprender

La persona periodista debe estar en continua tensión para aprender, para observar, para analizar, para valorar justamente, en definitiva para potenciar su cultura.

c. Un ser al servicio de los demás

La persona periodista si tiene sentido es porque su labor no está en función de su propio beneficio. Su beneficio es el servicio, quizá la información, seguro la sociedad.

Tiene que contribuir al bien común, al mejoramiento de los individuos, de la sociedad. 
d. Un ser maduro.

La madurez de la persona periodista, de cualquier persona pasa por su capacidad de amar (el periodista debe tener autoconocimiento, debe saber para qué hace una información, cómo y por qué), su capacidad de trabajar (el periodista debe desarrollar su capacidad de ser productivo y feliz), su capacidad de colaborar (el periodista es uno más de la sociedad, a ella tiene que servir) y finalmente seguridad en sí mismo y en lo que hace.

Esta reflexión humanística no significa una minusvaloración de las dimensiones tecnológicas, sociológicas e incluso positivas de la comunicación. Antes bien, las ilumina en sus principios, participando en el conocimiento profundo de la misma y apreciando, en la medida adecuada, sus diferentes dimensiones aportando el punto de vista de la persona como centro de toda comunicación.

\section{Referencias}

CANEL, Maria José \& Rodríguez ANDRÉS, Roberto. \& Sánchez Aranda. Madrid: CIS, Periodistas al descubierto. Retrato de los profesionales de la información, 2000.

CEBRIÁN, Mariano. Nuevas formas de comunicación: cibermedios y medios móviles. Comunicar, $n^{\circ} 33$, p. 10-13.

GARCÍA MATILLA, Agustín. Educación y comunicación. Escuela y Sociedad. Santander, Gobierno de Cantabria, Consejería de Educación y Juventud, 2001.

GARTON ASH, Timothy. Barcelona. Tusquets editores, Ensayos, retratos y crónicas de la Europa de los 90. 2000.

LAMUERDA, Maria. Estudiantes de periodismo y práctica profesionales. Comunicar, $\mathrm{n}^{\circ}$ 28, pp. 203-211, 2007.

LEÓNARD, André. Madrid, BAC: El fundamento de la moral, 1991.

HERNANDO, Bernardo. En qué ha quedado el cuarto poder. Cuadernos de Periodistas, $\mathrm{n}^{\circ}$ 1, pp. 73-87, 2004.

PASTOR, Maria Ángeles. Quiero ser periodista: tras las motivaciones de la profesión periodística. Comunicar, $\mathrm{n}^{\circ}$ 34, pp. 191-200, 2010. 
PÉREZ RODRÍGUEZ, Maria Amor. Barcelona: Paidós, Los nuevos lenguajes de la comunicación: Enseñar y aprender con los medios, 2004.

PÉREZ TORNERO, José Manuel. Barcelona: Paidós, Comunicación y Educación en la sociedad de la información, 2000.

RAMONET, Ignaci. Barcelona: Debolsillo, La golosina visual. ¿Estamos manipulados por la comunicación?, 2001

TOMASELLO, Michael. Madrid: Amorrortu, Los orígenes culturales de la cognición humana, 2007.

SÁNCHEZ TABERNERO, Alfonso: Los medios de comunicación y la sociedad del futuro. Nuestro Tiempo, n 601-602, pp. 23- 37, 2004. 